\title{
Pathology of antibiotic-treated human heart valve allografts
}

\author{
J.B. GAVIN ${ }^{1}, P$. B. HER DSON, J.L. MONRO, a nd \\ B. G. B A R R A T T - B O Y E S \\ Department of Pathology, University of Auckland, and Cardiothoracic Surgical Unit, \\ Green Lane Hospital, Auckland, New Zealand
}

\begin{abstract}
Gavin, J. B., Herdson, P. B., Monro, J. L., and Barratt-Boyes, B. G. (1973). Thorax, 28, 473-481. Pathology of antibiotic-treated human heart valve allografts. Forty-two human heart valves treated with an antibiotic solution were examined by light and electron microscopy up to 168 weeks after grafting in aortic, mitral, and tricuspid positions. There was a progressive degeneration of donor cells and by 40 days both fibroblasts and endothelial cells had vanished, leaving grafts virtually acellular. However, host inflammatory cells, together with fibrin and erythrocytes, infiltrated some regions. After 12 weeks macrophages were present in these focal collections of cells and were associated with the removal of intracuspal fibrin and the disruption of cuspal collagen. Avascular intimal fibrous sheaths of host tissue tapered from the margins of all grafts after six weeks and extended as much as half-way out of the cusp leaflets of some with consequent cusp thickening. Slow, progressive replacement fibrosis occurred along the deep surface of grafts but calcification of donor arterial wall was not observed. There was little invasion of the graft by fibroblasts from the intimal sheaths although macrophages were common along the interface between them and the underlying graft. These changes were qualitatively similar to those following chemical sterilization although intracuspal macrophage activity was generally much less and intimal fibrous sheaths were more extensive.
\end{abstract}

Heart valve allografts treated with antibiotic solution before placement have been found clinically to be superior to those sterilized chemically, and in particular they have a much lower incidence of cusp rupture. It is significant that leaflet failure has not so far been observed at Green Lane Hospital in antibiotic-treated aortic valve allografts regardless of site, although cusp rupture has occurred in $4.3 \%$ of antibiotic-treated pulmonary valve allografts placed in the mitral position. The clinical performance of untreated, chemically sterilized, and antibiotic-treated heart valve allografts in this series has been comprehensively reviewed elsewhere (Barratt-Boyes et al., 1969; Barratt-Boyes, 1971; Barratt-Boyes et al., 1972).

This paper describes the histopathology of antibiotic-treated human heart valve allografts and compares these findings with earlier studies of the pathology of chemically treated allografts

1 Reprint requests to : Dr J. B. Gavin, Department of Pathology, University of Auckland, Private Bag, Auckland, New Zealand from the same hospital (Smith, 1967; Gavin, Herdson, and Barratt-Boyes, 1972).

\section{MATERIAL AND METHODS}

Forty-two heart valves which had been used as allografts for from several hours to 168 weeks were examined. Sixteen were recovered when they were surgically replaced and 26 were recovered at necropsy following hospital death (22) or late death (4) from subdural haemorrhage, hepatitis or cardiac arrhythmia. Twenty-seven grafts were aortic valves used to replace aortic (18) or mitral (9) valves, and 15 were pulmonary valves used as grafts in the mitral (13) and tricuspid (2) positions.

The allografts recovered after mitral replacement had been sutured into non-rigid Tefion sleeves (11) and positioned on the left atrial side of the valve ring or, more recently, into Dacron-covered supporting metal stents (11) placed with the struts projecting into the left ventricle (Barratt-Boyes et al., 1972). The two pulmonary valves used for tricuspid valve replacement were also stent-mounted. All aortic valve replacements had been performed freehand. 
The valves to be used as allografts had been removed from cadavers of either sex aged between 16 and 81 years, and had been stored prior to insertion at $4^{\circ} \mathrm{C}$ for periods from 8 to 100 days in Hanks's balanced salt solution supplemented with 50 units of penicillin, $1 \mathrm{mg}$ of streptomycin, $1 \mathrm{mg}$ of kanamycin, and 25 units of amphotericin B in each millilitre of solution. Pieces of adjacent vessel wall were similarly treated and used to monitor the sterility of the preparation.

Allografts obtained at necropsy were placed in $5 \%$ phosphate-buffered formaldehyde, while those removed surgically were quickly placed in phosphatebuffered 5\% glutaraldehyde (pH 7.4). After 24 to 36 hours' fixation, central segments of each cusp with its supporting arterial wall were excised for light microscopy using consecutive paraffin sections stained with haematoxylin and eosin, van Gieson's stain, Weigert's elastin stain, alcian blue at $\mathrm{pH} 2.5$

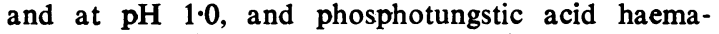
toxylin. Contiguous segments of tissue from 12 surgical specimens were post-fixed in $1 \%$ osmium tetroxide, and epoxy resin-embedded sections were prepared. These were stained with lead citrate and uranyl acetate for examination with a Philips EM300 electron microscope.

\section{RESULTS}

MACROSCOPIC APPEARANCES Allograft valves recovered up to six weeks after placement were generally unremarkable except for occasional small flecks of thrombus on the cusp leaflets. Beyond six weeks many grafts showed some opacity and thickening of the basal parts of the cusp leaflets corresponding to the intimal fibrous sheaths (Fig.
1). Occasional reddish and yellowish flecks $\stackrel{\overrightarrow{\vec{\sigma}}}{\stackrel{\overrightarrow{0}}{0}}$ in the cusp leaflets indictated infiltrations of $\overline{0}$ erythrocytes and fibrin. However, in all grafts

\section{T A B L E}

REASONS FOR REPLACEMENT OF HEART VALVE ALLOGRAFTS

\begin{tabular}{|c|c|c|c|}
\hline $\begin{array}{c}\text { Site } \\
\text { of } \\
\text { Graft }\end{array}$ & $\begin{array}{c}\text { Type } \\
\text { of } \\
\text { Mounting }\end{array}$ & $\begin{array}{c}\text { Months } \\
\text { since } \\
\text { Insertion }\end{array}$ & Reasons for Removal \\
\hline $\begin{array}{c}\text { Pulmonar } \\
\text { valves }\end{array}$ & \multirow{10}{*}{$\begin{array}{c}\text { Teflon } \\
\text { sleeve } \\
\text { Teflon } \\
\text { sleeve } \\
\text { Teflon } \\
\text { sleeve } \\
\text { Teflon } \\
\text { sleeve } \\
\text { Teflon } \\
\text { sleeve } \\
\text { Teflon } \\
\text { sleeve } \\
\text { Teflon } \\
\text { sleeve } \\
\text { Teflon } \\
\text { sleeve } \\
\text { Teflon } \\
\text { sleeve }\end{array}$} & & \multirow{10}{*}{$\begin{array}{l}\text { CI eversion of atrial end of } \\
\text { graft } \\
\text { Peripheral suture line leak } \\
\text { CI eversion of atrial end of } \\
\text { graft } \\
\text { CI eversion of atrial end of } \\
\text { graft } \\
\text { CI rupture of one cusp } \\
\text { leaflet } \\
\text { CI rupture of cusp leaflets } \\
\text { CI eversion of atrial end of } \\
\text { graft } \\
\text { CI rupture of one cusp } \\
\text { leaflet } \\
\text { CI eversion of atrial end of } \\
\text { graft }\end{array}$} \\
\hline Mitral & & $3 \cdot 5$ & \\
\hline Mitral & & 4 & \\
\hline Mitral & & 9 & \\
\hline Mitral & & 12 & \\
\hline Mitral & & 15 & \\
\hline Mitral & & 17 & \\
\hline Mitral & & 19 & \\
\hline Mitral & & 28 & \\
\hline Mitral & & 32 & \\
\hline \multirow{2}{*}{$\begin{array}{l}\text { Aortic } \\
\text { valves } \\
\text { Aortic }\end{array}$} & & & \multirow{6}{*}{$\begin{array}{l}\text { CI following surgical } \\
\text { malplacement } \\
\text { Graft too small } \\
\text { CI due to redilatation of } \\
\text { aortic root } \\
\text { CI following bacterial } \\
\text { endocarditis } \\
\text { CI following surgical } \\
\text { malplacement } \\
\text { Peripheral suture line leak } \\
\text { CI following fungal } \\
\text { endocarditis }\end{array}$} \\
\hline & Freehand & 0.75 & \\
\hline $\begin{array}{l}\text { Mitral } \\
\text { Aortic }\end{array}$ & $\begin{array}{l}\text { Stent } \\
\text { Freehand }\end{array}$ & $\begin{array}{l}1 \cdot 5 \\
5 \cdot 5\end{array}$ & \\
\hline Mitral & $\begin{array}{l}\text { Teflon } \\
\text { sleeve }\end{array}$ & 12 & \\
\hline Aortic & Freehand & 24 & \\
\hline $\begin{array}{l}\text { Aortic } \\
\text { Aortic }\end{array}$ & $\begin{array}{l}\text { Freehand } \\
\text { Freehand }\end{array}$ & $\begin{array}{l}35 \\
39\end{array}$ & \\
\hline
\end{tabular}

$\overline{C I}=$ central incompetence 
the pliability of the leaflets was normal and calcification was not evident.

The 16 grafts removed surgically were incom. petent while the remainder were competent. The reasons for surgical replacement are summarized in the Table. It is noteworthy that 9 of the 13 pulmonary valves recovered from the mitral position were incompetent due to failure of the graft valve per se. This was due in five cases to an hour-glass deformity of the Teflon-wrapped graft placed in the left atrium with eversion of the atrial end of the graft from its supporting sleeve (Barratt-Boyes et al., 1972), and in three instances one or more cusp leaflets had ruptured. For these reasons pulmonary valves are no longer used as grafts in the mitral area. In contrast, surgical factors (3) and endocarditis (2) were the main reasons for replacement of the seven aortic valve allografts.

MICROSCOPIC APPEARANCES All grafts showed changes within the graft itself, together with a cellular reaction along the host/graft interface after a few days and/or a proliferation of fibrous sheaths over the intimal surfaces of the grafts after three weeks.
Graft reaction Although Dacron mesh intervened between host and donor tissue in the 24 grafts from atrioventricular sites, histological changes observed at the host/graft interface were similar in all specimens. Organizing granulation tissue developed and slowly but progressively extended with increasing duration of the graft to replace the deeper parts of the donor arterial sleeve. An infiltrate of macrophages, lymphocytes, and plasma cells was always present along the interface and occasional foreign body giant cells were associated with suture material. The virtual acellularity and densely fibrous nature of donor arterial sleeve distinguished it from the cellular, mucopolysaccharide-rich and less fibrous host tissue which extended into it.

Intimal fibrous sheaths Deposits of fibrin along the graft margins became organized to form avascular collagenous sheaths which extended toward and sometimes onto the bases of the cusp leaflets. These sheaths varied greatly in extent even between the cusps of the same graft. In 8 of the 19 grafts present longer than six weeks, intimal fibrous sheaths extended up to half-way out the cusp leaflets, considerably thickening their

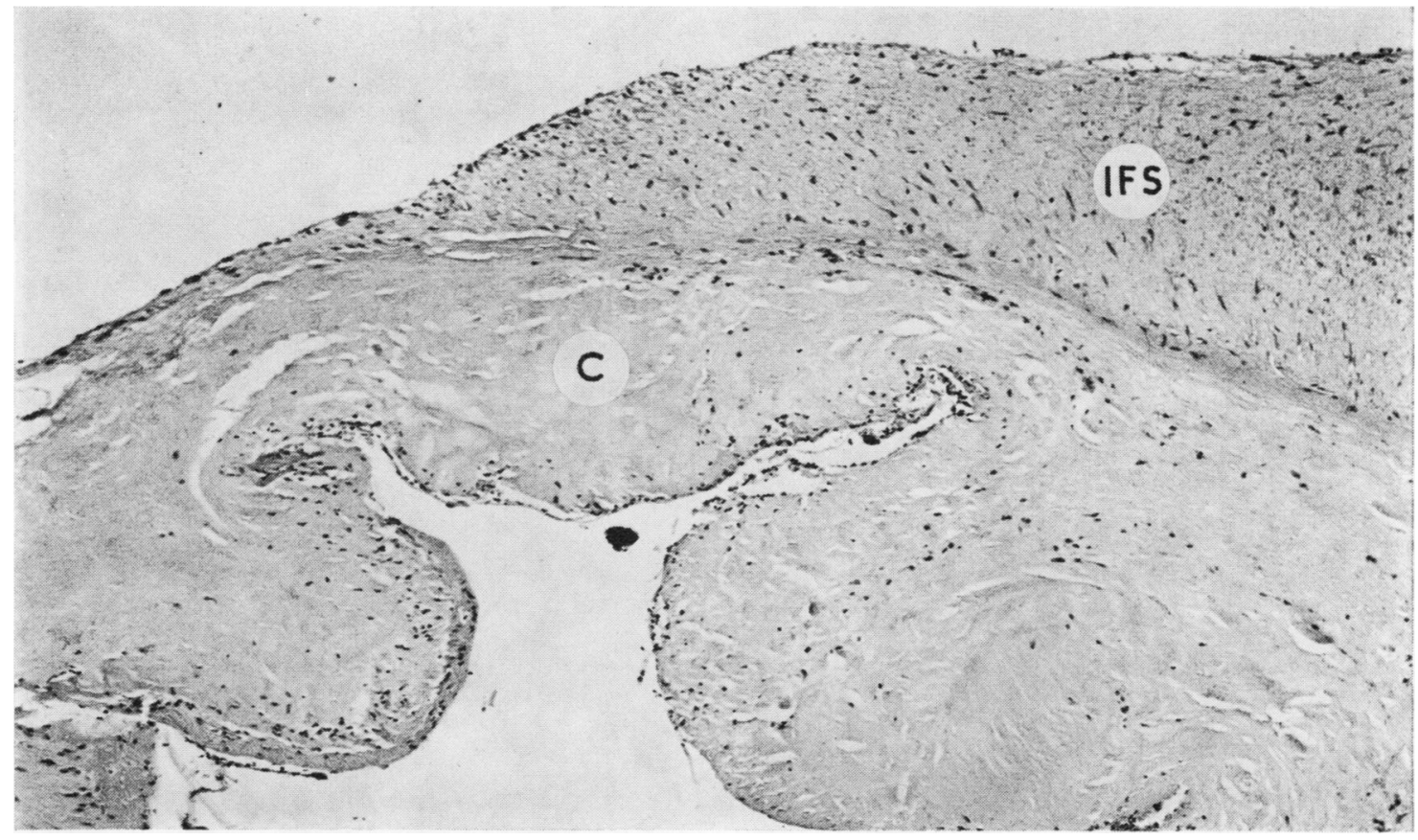

FIG. 2. Section through one cusp leaflet $(C)$ of the allograft shown in Fig. 1. An intimal fibrous sheath (IFS) tapers from the base of the cusp (right) over its convex surface. Haematoxylin and eosin $\times 90$ 


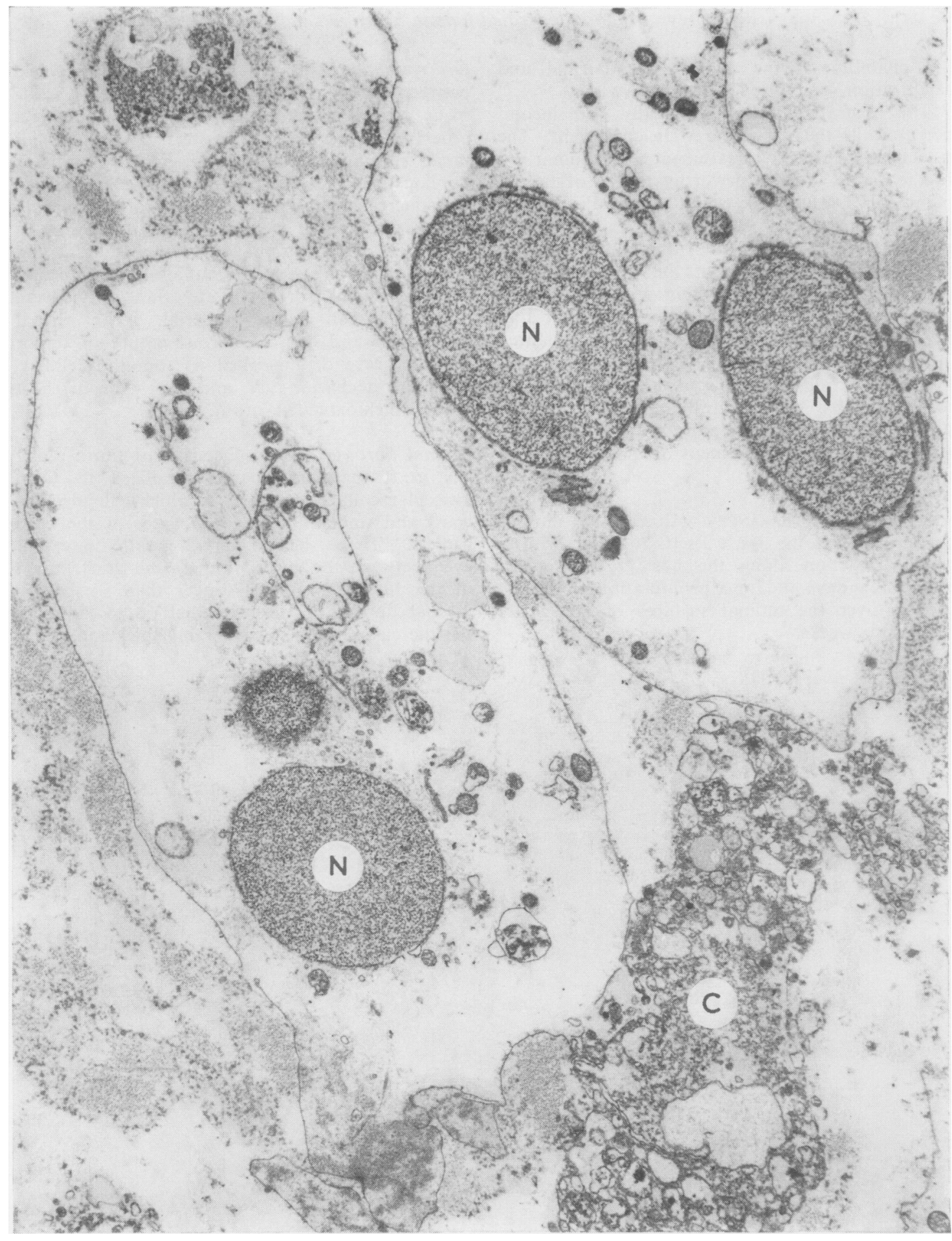

FIG. 3. Pyknotic nuclear remnants $(N)$ lie within degenerate fibroblasts which have discharged most of their cytoplasm $(C)$ into the surrounding cusp matrix of this aortic valve stored in antibiotic solution for 24 days before insertion into the mitral position for several hours. E.M. $\times 16,500$ 


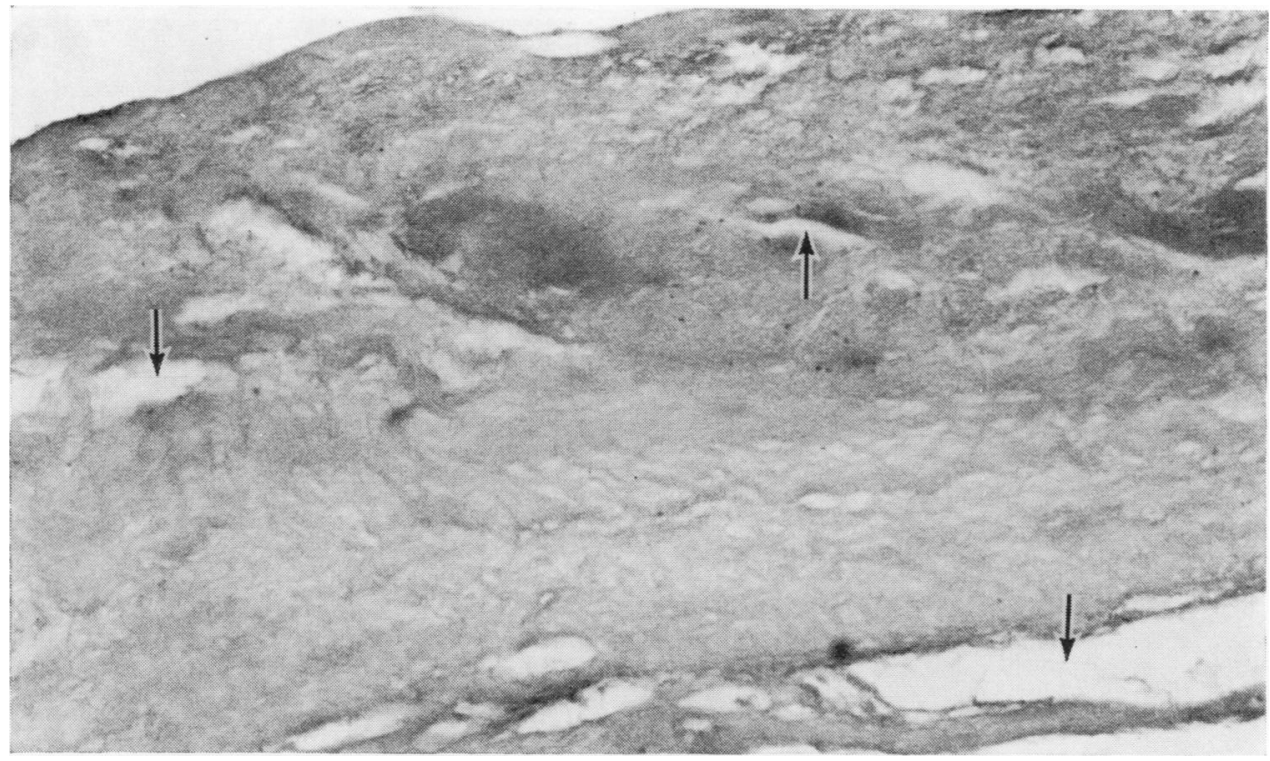

FIG. 4. Segment of cusp leaflet from a pulmonary valve stored in antibiotic solution for 26 days before placement in the mitral position for 130 weeks. It shows a more or less uniform fibrous matrix with some separation of fibre bundles (arrows). This area is totally devoid of cells. Haematoxylin and eosin $\times 260$

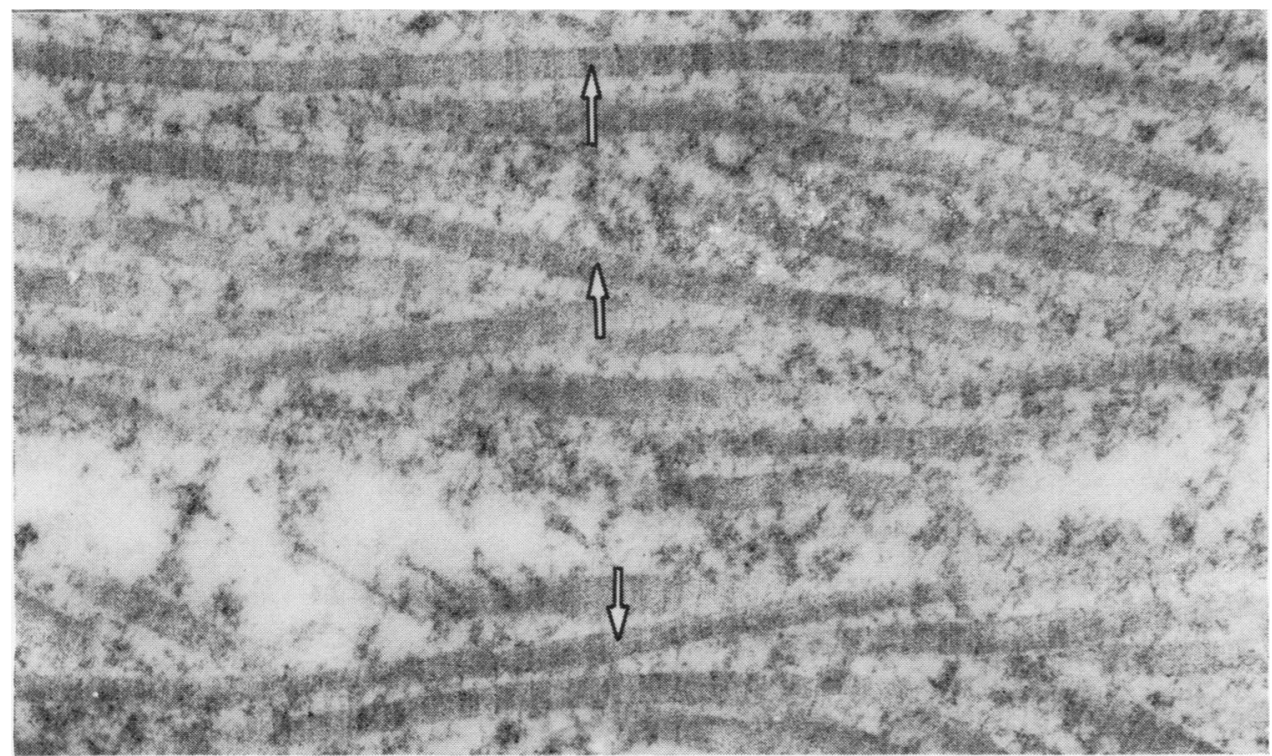

FIG. 5. Characteristically striated collagen fibres (arrows) in the cusp of an aortic valve allograft stored for eight days in antibiotic solution and used as a mitral valve replacement for two years. E.M. $\times 60,000$ 


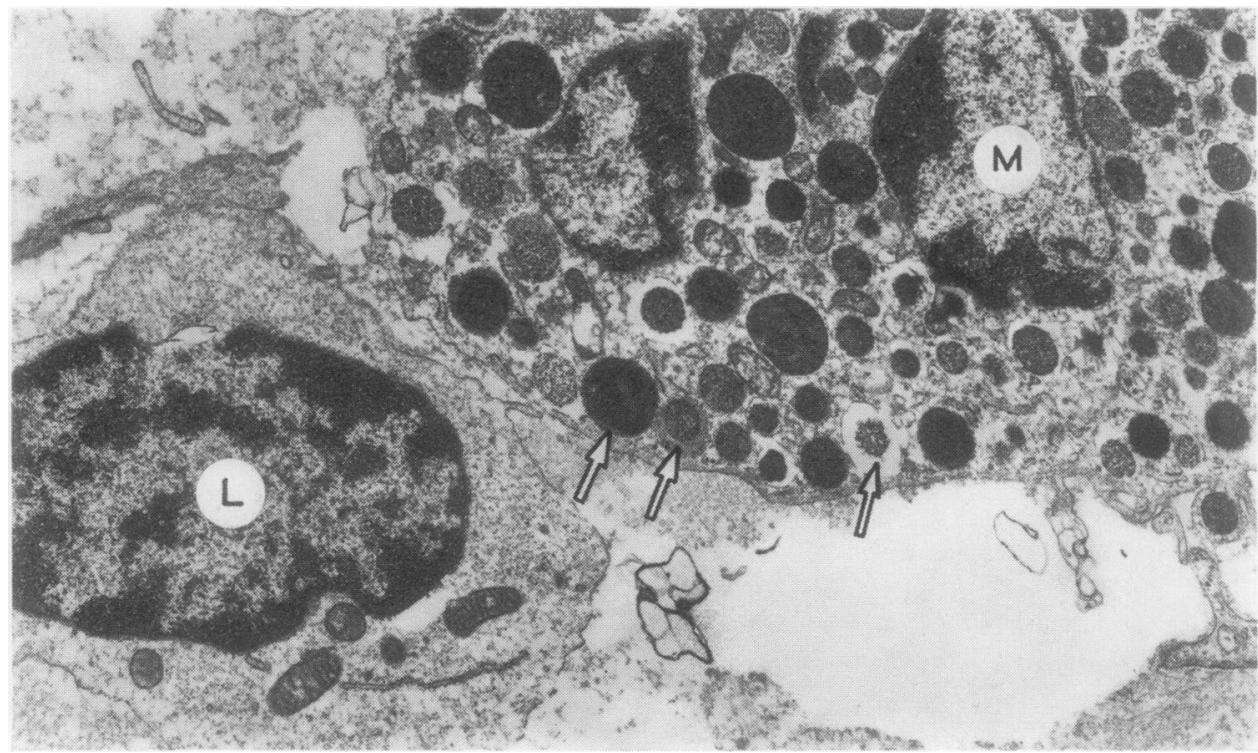

FIG. 6. Portions of a lymphocyte $(L)$ and a macrophage $(M)$ within the cusp of an aortic valve which had been stored for eight days in antibiotic solution and used for two years as a mitral valve replacement. The macrophage contains numerous lysosome-like bodies (arrows). E.M. $\times 22,000$

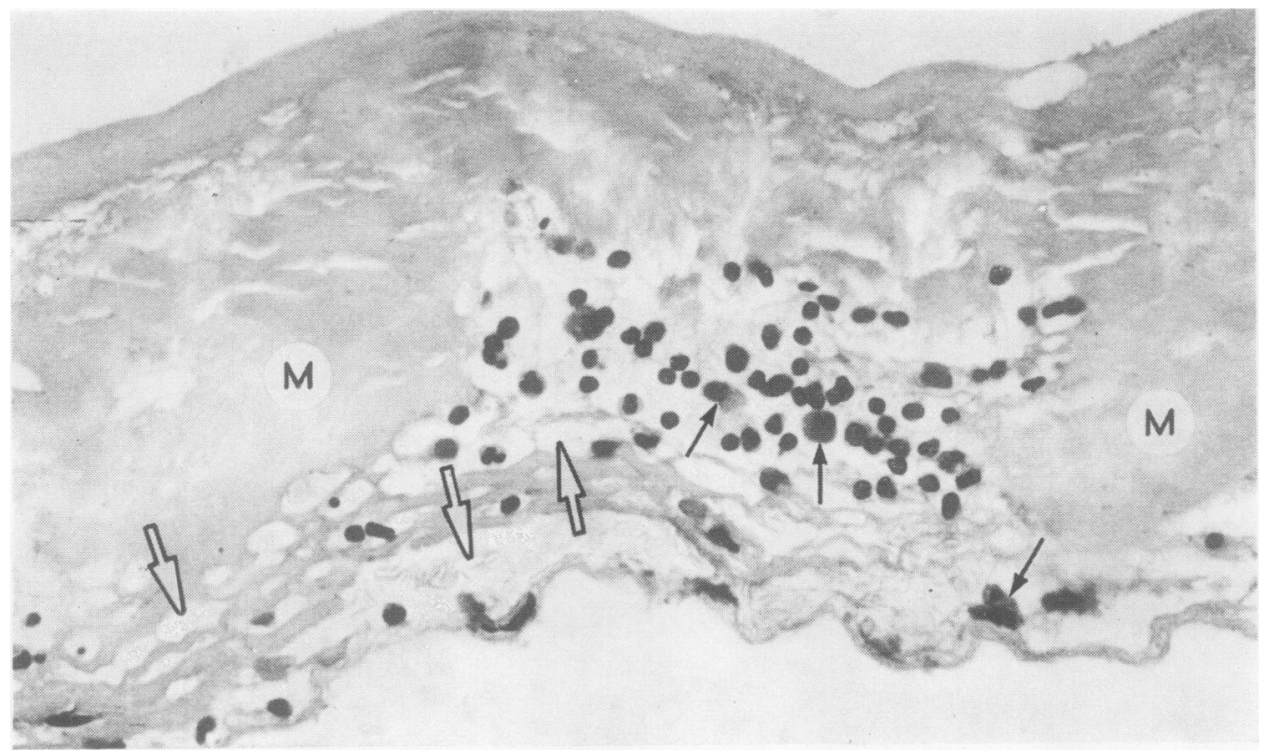

FIG. 7. A focal collection of macrophages (small arrows) and lymphocytes in another part of the same cusp of the allograft illustrated in Fig. 4. The cusp matrix $(M)$ contains lacunae (large arrows) in which the cells lie. Haematoxylin and eosin $\times \mathbf{2 6 0}$ 
proximal parts (Figs 1 and 2). Fibroblasts and considerable quantities of mucopolysacchariderich ground substance were present in these sheaths which contained much less collagen than the underlying, predominantly acellular graft. Macrophages were also present along this clearly defined junction. Endothelial cells, continuous with those of the host, covered the intimal fibrous sheaths.

Changes in the graft Grafts recovered after only one or two days in the recipient and which had been stored for 20 or more days in antibiotic solution showed slight interfibrillar oedema, the loss of virtually all endothelial cells, and degeneration of fibroblasts. Those donor cells remaining contained pyknotic nuclei and showed advanced cytoplasmic disorganization and disintegration (Fig. 3). The loss of fibroblasts was progressive and appeared to depend more on the total time since collection of the graft rather than time either in storage or in the recipient. By 40 days after collection all light microscopic evidence of fibroblasts had disappeared (Fig. 4) although degenerate donor muscle cells persisted until removed by host phagocytes.

While some separation of the fibrous elements of the cusps was observed, the ultrastructure of individual elastic and collagenous (Fig. 5) fibres was indistinguishable from normal.

Focal infiltrations of erythrocytes and fibrin were observed in all grafts in place for more than one day, but their number and extent varied greatly from graft to graft. Virtually all grafts also showed focal infiltrations of leucocytes which included many lymphocytes (Fig. 6) with smaller numbers of eosinophils and neutrophils. In grafts removed after three months, macrophages with ovoid nuclei and extensive cytoplasm containing lysosomes could also be identified among these cells (Figs 6 and 7). These macrophages often lay in lacunae within the cusp matrix (Fig. 7) and were most common in regions infiltrated by fibrin. In some long-term grafts the macrophages appeared to be resorbing both the fibrin infiltrate and the fibrous matrix of the cusp (Fig. 7).

The number of sites of mononuclear cell infiltration and the apparent activity of macrophages within them varied widely from graft to graft and even between various parts of the same graft. The variation in histological appearance within a single cusp is illustrated in Figures 4 and 7. Pulmonary valves in the mitral position were generally more extensively infiltrated by fibrin and macrophages than other groups, but differences between grafts could not be correlated with any known characteristics of either the donors or recipients.

\section{DISCUSSION}

Qualitatively the histopathological changes described in the present study are similar to those observed in chemically sterilized valves (Hudson, 1966; Smith, 1967; Reichenbach, Mohri, and Merendino, 1969; Gavin et al., 1972) but there are important quantitative differences. In these antibiotic-treated grafts the degree to which intimal fibrous sheaths extend onto cusp leaflets is generally much greater, and the extent of macrophage activity in the cusps is generally much less. These factors are the likely basis for the much reduced tendency to cusp rupture of antibiotictreated valves.

Although the intimal fibrous sheaths extended onto the cusp leaflets of antibiotic-treated allografts to a much greater extent than those sterilized chemically, over periods extending to 168 weeks, fibroblasts did not extend throughout the entire width and thickness of the leaflets as they may do in untreated grafts (Gavin, Hitchcock, Herdson, and Barratt-Boyes, 1973a). The distinct and regular interface observed between these sheaths and underlying donor tissue suggests that antibiotic treatment may alter the ground substance of the graft in a way which slows or inhibits the proliferation of host fibroblasts into it. Indeed, this may not be a disadvantage since sheaths of limited extent could provide strength to the hinge region of the cusps without the extensive overall leaflet thickening which is seen in some untreated valves. This feature, and the observed lack of fine structural changes in collagen and elastin, the freedom from calcification, and the absence so far of leaflet failure when aortic valve allografts are placed in the aortic and mitral positions and when pulmonary valve grafts are used in the tricuspid position, indicates that appropriately placed antibiotic-treated allografts have a good prognosis.

So far leaflet failure has been observed only in pulmonary valves placed in the mitral position in which fibrin infiltration into the cusp leaflets was most frequently observed. This is consistent both with the more delicate nature of the pulmonary valve compared with the aortic valve and with the greater pressures they are subjected to when inserted into the left compared with the right side of the heart. It also supports the hypothesis previously advanced for chemically sterilized valves (Gavin et al., 1972) that cusp rupture follows disruption of the cusp matrix by macrophages stimulated by the presence of fibrin within it. From the 
histological similarities it is conceivable that cusp rupture may eventually occur in aortic valve grafts and in pulmonary valve grafts in the tricuspid position. However, this possibility is much diminished in the former group by the more robust architecture of aortic valve leaflets and their 50 to $100 \%$ greater mass (Seelye, 1972) and in the latter group by the lower pressure differences in the right side of the heart.

The wide variation between similarly treated grafts is less easy to explain. Although Mohri et al. (1967) have demonstrated and discussed the low antigenicity of the homologous aortic valve and the possibility of the subcoronary site being privileged, it is difficult to ignore immunological considerations when the host/graft interface involves both lymphocytes and plasma cells and when lymphocytes are invariably present in the cellular infiltrates within the cusps. It may be that the low degree of graft rejection seen in heart valve allografts is also related to the limited access of these immunologically active cells to the avascular donor tissue. However, when such cells do enter the graft in a focal infiltrate it is conceivable that their subsequent activity might be influenced by antigenic factors, such as the histocompatibility antigens of donor cells or cell remnants (Gowans, 1970). Similarly, it is only possible to speculate on the reasons for differences between different parts of individual grafts. Local differences in stress may affect the extent and thickness of intimal fibrous sheaths, and the degree of inflammatory cell infiltration could conceivably be related to localized injury or alterations of the graft surface.

While it is known that chemical sterilization destroys donor cells (Hudson, 1966; Smith, 1967 ; Gavin et al., 1972), it has been suggested that a milder form of sterilization using antibiotics may preserve the viability of donor fibroblasts (Angell, Mermet, and Buch, 1970; Al-Janabi, GonzalezLavin, Neirotti, and Ross, 1972), as has been reported in fresh unsterilized grafts (Mohri, Reichenbach, Barnes, and Merendino, 1968; Kosek, Iben, Shumway, and Angell, 1969), and that this may be the basis for the improved results with antibiotic-treated allografts. However, prolonged survival of donor cells within the recipient does not follow storage of allografts in antibiotics at the concentrations and for the intervals used for the material studied, although degenerate but light-microscopically normal fibroblasts were often present at the time of insertion. A parallel electron microscopic study of changes in allografts stored in this antibiotic solution for 7 to 21 days has also revealed fine structural changes affecting many fibroblasts which are inconsistent with their viability (Gavin, Wall, and Monro, 1973b).

Our findings do not discount reports of fibroblast survival by Angell et al. (1970) for they used different concentrations of antibiotics and demonstrated cell viability by tissue culture which is superior to morphological methods for this pur- $\vec{\circ}$ pose. However, Al-Janabi et al. (1972) used the same preparative procedures as we have and $\vec{\omega}$ reported that $73 \%$ of graft cells take up tritiated thymidine after 24 hours and $21 \%$ do so after $63 \vec{x}$ days in this antibiotic solution. Our study suggests $\underset{\infty}{N}$ that despite the evidence of viability at the time $\rightarrow$ of insertion, donor fibroblasts disappear from $A$ antibiotic-treated grafts after 40 days in the $\omega$

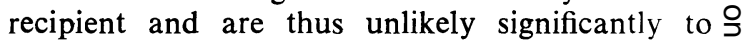
influence its long-term survival.

Dr. R. G. Palmer and the staff of the Department of Pathology, Green Lane Hospital kindly provided $\vec{\theta}$ much of the material studied. Dr. R. N. Seelye, Mr. D. Baird, Sister Ronaldson, Mr. E. E. Wheeler, Mrs. P. T. Broughton, Mrs. F. M. Wall, and Miss L. A. Taylor gave invaluable assistance in this investigation, which received financial support from the Medical Research Council of New Zealand and from the Auckland Medical Research Foundation.

\section{REFERENCES}

Al-Janabi, N., Gonzalez-Lavin, L., Neirotti, R., and Ross, D. N. (1972). Viability of fresh aortic valve homografts: A quantitative assessment. Thorax, 27, 83.

Angell, W. W., Mermet, B., and Buch, W. (1970). Antibiotic sterilization of fresh homograft valves. Circulation, $42, \stackrel{\square}{\times}$ Suppl. 3, p. 130 (Abstract).

Barratt-Boyes, B. G. (1971). Long-term follow-up of aortic valvar grafts. British Heart Journal, 33, Suppl, p. 60.

—_, Roche, A. H. G., Agnew, T. M., Cole, D., Kerr. A., Monro, J. L., Lowe, J. B., and Brandt, P. W. T. (1972). 응 Homograft valves. Medical Journal of Australia, 2, Special Suppl.: Proc. int. Cardiology and Cardiac $\frac{D}{O}$ Surgery Conference, Melbourne, 1971, p. 38. (Aug. 12, ․ㅡ․ 1972).

, - Brandt, P. W. T., Smith, J. C., and Lowe. J. B. (1969). Aortic homograft valve replacement. A long-term N follow-up of an initial series of 101 patients. Circulation, N 40, 763.

Gavin, J. B., Herdson, P. B., and Barratt-Boyes, B. G. (1972). The pathology of chemically-sterilized humane heart valve allografts. Pathology, 4, 175.

, Hitchcock, G. C., Herdson, P. B., and Barratt-Boyes, $\stackrel{\mathscr{S}}{+}$ B. G. (1973a). The histopathology of "fresh" human 7 heart valve allografts. Thorax, in press.

- _ - Wall, F. M., and Monro, J. L. (1973b). Fine structural $\vec{D}$ changes in heart valve allografts stored in antibiotic $\frac{\varrho}{\Phi}$ solutions. Thorax, in press.

Gowans, J. L. (1970). The immunology of tissue transplantation. In General Pathology, 4th edition edited by $\mathrm{H}$. W. Florey, p. 1162. Lloyd-Luke, London. 
Hudson, R. E. B. (1966). Pathology of the human aortic valve homograft. British Heart Journal, 28, 291.

Kosek, J. C., Iben, A. B., Shumway, N. E., and Angell, W. W. (1969). Morphology of fresh heart valve homografts. Surgery, 66, 269.

Mohri, H., Reichenbach, D. D., Barnes, R. W., and Merendino, K. A. (1968). Homologous aortic valve transplantation. Alterations in viable and nonviable valves. Journal of Thoracic and Cardiovascular Surgery, 56, 767. ,$--\frac{}{2}$, Nelson, R. J., and Merendino, K. A. (1967). Studies of antigenicity of the homologous aortic valve. Journal of Thoracic and Cardiovascular Surgery, $54,564$.

Reichenbach, D. D., Mohri, H., and Merendino, K. A. (1969). Pathological changes in human aortic valve homografts. Circulation, 39, Suppl. I, p. 47.

Seelye, R. N. (1972). Personal communication.

Smith, J. C. (1967). The pathology of human aortic valve homografts. Thorax, $22,114$. 